\title{
THE SENSITIVITY TEST OF MYCOBACTERIUM TUBERCULOSIS ISOLATES FROM SUSPECT TUBERCULOSIS PATIENTS TO THE SEROMUCOUS OF SNAIL AND CHITOSAN AS AN ALTERNATIVE ANTI-TUBERCULOSIS DRUGS
}

\author{
YUSUP SUBAGIO SUTANTO ${ }^{1,2 *}$, MAGDALENA SUTANTO ${ }^{3}$, AGNES SRI HARTI ${ }^{4}$, NONY PUSPAWATI ${ }^{5}$ \\ ${ }^{1}$ Department of Pulmonology and Respiratory Medicine, Faculty of Medicine, Sebelas Maret University of Surakarta, Indonesia. \\ ${ }^{23}$ District General Hospital of Surakarta City, Indonesia. ${ }^{4}$ Departemen of Nursing, Kusuma Husada University of Surakarta, \\ Indonesia. ${ }^{5}$ Department of Faculty of Health Science, University of Setia Budi (Universitas Setia Budi), Surakarta, Indonesia. \\ Email: dr_yusupsubagio@yahoo.com
}

Received: 12 May 2020, Revised and Accepted: 13 July 2020

Objective: The purpose of this research is to study the sensitivity of Mycobacterium tuberculosis (MTB) isolates from suspect TB patients to seromucous of snail and chitosan as an alternative to anti-TB drugs.

Methods: The research methods include management specimen, freeze-drying of snail seromucous; formulation of dosage preparation; identification of MTB isolates; and sensitivity testing of MTB isolates to snail seromucous, chitosan, and streptomycin, isoniazid, rifampicin, and ethambutol (SIRE).

Results: The characteristics of respondents by sex and age are the majority of male respondents and productive adult age that is 26 years-52 years. MTB isolates used in the study were obtained from the results of the screening of sputum samples of suspect TB patients through microscopic smear examination and molecular rapid test using GeneXpert tools. MTB isolates in patients suspect TB are resistant against seromucous of snails and chitosan that it is compared with SIRE. The dosage of snail seromucous is $8000 \mathrm{mg} / \mathrm{l}$, chitosan $2 \%$ is $800 \mathrm{mg} / \mathrm{l}$, and SIRE, respectively (rifampicin $8000 \mathrm{mg} / \mathrm{l}$, isoniazid $20 \mathrm{mg} / \mathrm{l}$, ethambutol $200 \mathrm{mg} / \mathrm{l}$, streptomycin $800 \mathrm{mg} / \mathrm{l}$ ).

Conclusion: MTB isolates from patients suspect who TB is resistant to seromucous of snail (8000 mg/l) and chitosan (800 mg/l).

Keywords: Sensitivity, Isolates, Mycobacterium tuberculosis, Snail seromucous, Chitosan, Streptomycin, Isoniazid, Rifampicin, Ethambutol.

(c) 2020 The Authors. Published by Innovare Academic Sciences Pvt Ltd. This is an open access article under the CC BY license (http://creativecommons. org/licenses/by/4. 0/) DOI: http://dx.doi.org/10.22159/ajpcr.2020.v13i10.38266

\section{INTRODUCTION}

Tuberculosis (TB) is an infection caused by Mycobacterium tuberculosis (MTB) and transmission through droplets of sputum sufferers or suspect TB in the air. Organs that are infected are generally the lungs so that it is called pulmonary $\mathrm{TB}$, but it can also attack other organs, namely, lymph, brain membranes, skin, bones, joints, intestines, and kidneys, so it is called extrapulmonary disease. TB can be identified through suspected TB, including coughing continuously for 2-3 weeks or more accompanied by blood, shortness of breath, weak body, decreased appetite, weight loss, night sweats even without activity, and fever for more than a month.

TB treatment lasts long enough that is at least 6 months of treatment which has an impact on the emergence of germ resistance and TB treatment does not work because patients drop out of treatment or take medication irregularly so that multi drugs resistance tuberculosis (MDR-Tb) occurs. Most MDR-Tb occurs due to lack of adherence in the treatment of $\mathrm{T}$. The resistance that occurs can be in the form of primary resistance and secondary resistance. Early detection of MDR-Tb and starting therapy as early as possible is an important factor for achieving therapeutic success.

TB can be cured by administering appropriate anti-tuberculosis drugs (ATD). First-line treatment for TB usually uses isoniazid (INH), rifampicin (RIF), pyrazinamide (PZA), and ethambutol (EB) or streptomycin (SM) as the main choice. There are side effects in MDR-TB therapy and the correlation between cure rates and resistance to antituberculosis medication so that a psychological, social management approach is needed in MDR-TB patients and the presence of a bacterial profile related to resistance against antibiotics against TB treatment.
Snails (Achatina fulica Ferussac) contain bioactive compounds found in seromucous or hemolymph. Seromucous of snails have bioactivity as HeLa antitumor and are non-toxic to lymphocyte cells, it can even stimulate lymphocyte proliferation. Snails seromucous as glycoprotein containing carbohydrate; fraction $\alpha-1$ globulin oromucoid; glycans, peptides, glycopeptides, and chondroitin sulfate. The snail chondroitin sulfate can function as immunomodulation and immunosuppressant [1]. Another substance of snails seromucous is content of glycosaminoglycans, heparin, heparin sulfate, sulfate dermal, and hyaluronic acid; can function as stabilizer cofactors and/ or coreceptor for growth factors, cytokines, and chemokines; enzyme activity regulator; molecular labeling in response to cellular damage in the process of wound healing, infection, tumorigenesis; target for bacterial, viral, and parasitic virulence factors; as well as the immune system [2]. Achasin protein in the snail has important biological functions, among others, as a bacterial binding protein (enzyme) receptor [3]. The concentration snail mucus $100 \%$ and $5 \%$ snail slime cream have an effective effect on accelerating the duration of healing of second-degree (A) burns [4].

Chitosan is a polysaccharide that is found in abundant quantities in nature, especially in waste shrimp shells, crab skin. Chitosan is $\beta$-(1.4)2 amino-2 deoxy D-glucopyranose as a product of chitin deacetylation. The uniqueness of chitosan is polycationic so that it can suppress the growth rate of diarrheagenic Escherichia coli in vitro [5]. Synbiotic (Chitooligosaccharide and Lactobacillus acidophilus) bio preparation in yogurt can reduce cholesterol levels in vitro and in vivo [6,7]. Chitosan has been widely used in biomedical and pharmaceutical fields because it is biodegradable, non-toxic, non-immunogenic, and biocompatible with animal body tissues [8]. The combination of $100 \%$ snail mucous 
and chitosan $1.5 \%$ with ratio $1: 2$ gives the optimum wound healing rate in the in vivo test. The synergistic effect of snail mucous and chitosan on Staphylococcus aureus in vitro [9].

The presence of bioactive compounds in snail seromucous and chitosan can stimulate cellular immune function in lymphocyte proliferation and the production of reactive oxygen intermediated macrophages which can increase the body's immunity against intracellular facultative bacterial infection including TB infection. The high incidence of TB infection is related to the level of resistance of MTB to ATD and there is no research conducted on the potential of snail and chitosan seromucous as an alternative to ATD. Research on the study of the sensitivity of MTB isolates from patients suspected of TB to snails seromucous and chitosan as an alternative ATD needs to support the treatment of TB infection and the development of new ATD other than SIRE that have been used.

The purpose of this research is to study the sensitivity of MTB isolates from suspect TB patients against seromucous of snails and chitosan as an alternative to ATD.

\section{METHODS}

\section{Management sampling}

Seromucous freeze-dried of snail was collected from local snails (A. fulica Ferussac) as many as 10-50 snails then seromucous or hemolymph of snail taken by opening the tip of the shell and the liquid that comes out is collected in a flask, then centrifuged $3000 \mathrm{rpm} 30 \mathrm{~min}$. Seromucous fluid obtained was then carried out the freeze-drying process at $48^{\circ} \mathrm{C}$ for $24 \mathrm{~h}$. The freeze-drying process of snail seromucous is carried out at the Laboratory of Pharmaceutics at Muhammadiyah University, Surakarta.

Chitosan powder was performed from Biotecherusindo, Indonesia. Chitosan used $2 \%$ was dissolved in $5 \%$ acetic acid solution.

Clinical specimens were collected from patients with suspected TB at Surakarta City Central General Hospital.

\section{MTB culture and identification}

The screening test was performed by microscopic examination of Ziehl-Neelsen (ZN) staining and Molecular Quick Test - GeneXpert instrument in accordance with relevance guidelines. The positive MTB isolates were subjected to cultivation with Lowenstein-Jensen (LJ) medium (HiMedia, M162 product). Suspension of bacteria obtained a concentration of $1 \mathrm{mg} / \mathrm{mL}$ or McFarland 0.5-1.0. Suspension of germs made $10^{-3}$ and $10^{-5}$ dilutions. ATD with dose: RIF ( $\left.8000 \mathrm{mg} / \mathrm{l}\right)$, INH (20 mg/l), EB (200 mg/l), SM (800 g/l), PNB (2.25 ml/l), and negative control as LJ media without ATD [10]. Until now, there has been no research on the effectiveness freeze-dried seromucous of snail and chitosan bioactive compounds as ATD against MTB so that the snail seromucous dosage is analogous to RIF $8000 \mathrm{mg} / \mathrm{l}$ and the chitosan dosage is analogous to SM $800 \mathrm{mg} / \mathrm{l}$. Pre-sensitivity test with specimen management, culture process, and identification takes 3-6 weeks. The growth isolates were then have taken randomly of number and code samples for use in research treatments.

\section{Drug susceptibility testing (DST)}

MTB sensitivity test procedure to determine whether the isolate is resistant or sensitive against seromucous of the snail, chitosan, and SIRE. DST was performed using the MTB system [10]. All steps were performed by trained and specialized persons in a biosafety cabinet in accordance with relevant guidelines. The colonies of MTB were swept from the agar plates and suspended in sterile saline containing $0.2 \%$ Tween and glass beads. After vortexing for at least 30 s to break up organisms clumps, the bacterial suspension was stayed for $15 \mathrm{~min}$ at room temperature to allow any remaining clumps to settle to the precipitations, and the supernatant was adjusted to then a suspension with a turbidity of 0.5-1.0 McFarland standard using a nephelometer. The dilution suspension was performed to $10^{-3}$ and $10^{-5}$. Stock solutions and working solutions were prepared. One hundred microliter suspension of the subsequent suspension was inoculated to each tube of LJ media that contained freeze-dried seromucous, chitosan, and ATD, including SIRE. The tube culture was incubated at $37^{\circ} \mathrm{C}$ for $28-42$ days and results of the percentage of resistance can be known.

\section{RESULTS AND DISCUSSION}

\section{Isolation and identification of MTB Isolates}

The screening tests conducted in this study included microscopic examination according to IUALTD; culture on LJ media added PNB and MPT-64 rapid test on five TB isolates. Isolates of MTB were obtained from culture-positive MTB cases and non-tuberculosis mycobacteria (NTM) were excluded from the study. All the MTB isolates were validated by both the growth test on p-nitrobenzoic acid (PNB) and MPT-64 antigen detection kit, as shown in Table 1.

The most TB diagnosis measures practiced in the area are direct microscopy for acid-fast bacilli (AFB). AFB microscopic examination is a simple examination by the $\mathrm{ZN}$ staining method, which is from a sputum sample made smear preparations. The results of smear microscopic carried out using the International Union against Tuberculosis and Lung Disease scale. MTB is known AFB in the form of a straight rod with a width of $0.3-0.6 \mu$ and a length of 1-4 $\mu$, non-motile, non-sporicidal, and not encapsulated. The cell wall is complex, consisting of $60 \%$ of the fat layer and is composed of mycolic acid, complex waxes (complex- waxes), trehalose-6,6-dimikolat, arabinomannan, and mycobacterial sulfolipids which play an important role in virulence. Mycolic acid is a chain of fatty acids. Mycolic acid is a long-chain fatty acid (C60-C90) that binds to arabinogalactan. The basic structure of a typical and complex cell wall such as Gram-positive bacteria, the inner layer of the membrane is covered with a thick layer of peptidoglycan but has a more complex structure compared to other Gram-positive so that MTB is known to be acid-resistant. The microscopic method as a non-expensive and suitable method for the diagnosis of TB. The overall sensitivity and false-negative results of the microscopic examination were $66.0 \%$ and $34.0 \%$, respectively. In addition, the overall specificity and false-positive results would be $94.6 \%$ and $5.4 \%$, respectively. There was a report for comparing the positive samples in microscopy and culture methods regarding the culture as a gold standard method and AFB were found in only $46 \%$ of culture-positive smears and in the range of $53-80 \%$ of the first smear of positive sputum samples. The sensitivity and specificity of the sputum smears compared to the culture method were $80 \%$ and 94.1\% [11].

Rapid MPT64 ICT test is an immunological test that can be used to identify new and old MTB isolates with the record that the isolate is still alive; it has high sensitivity and specificity, so it becomes an alternative for the identification of MTB and MDR-TB. The antigen component in the cell wall and cytoplasm consists of lipid, polysaccharide, and protein components. There are also groups of

Table 1: Results of MTB culture and identification

\begin{tabular}{|c|c|c|c|c|c|c|c|}
\hline No & Code sample & Sex & Age (year) & Culture results & PNB & MPT-64 & Result \\
\hline 1 & 122 & Male & 40 & 7 colonies & Negatif & Positif & $\mathrm{MTb}$ \\
\hline 2 & 172 & Female & 52 & 12 colonies & Negatif & Positif & $\mathrm{MTb}$ \\
\hline 3 & 197 & Male & 26 & $2+$ & Negatif & Positif & $\mathrm{MTb}$ \\
\hline 4 & 200 & Male & 44 & $2+$ & Negatif & Positif & $\mathrm{MTb}$ \\
\hline 5 & 218 & Male & 38 & $4+$ & Negatif & Positif & $\mathrm{MTb}$ \\
\hline
\end{tabular}


antigens that are secreted and not secreted (somatic), for example antigens secreted by living bacilli, namely $30,000 \mathrm{kDa}$ antigens, MTP40 protein, and others. Currently known as purified antigens with molecular weights of 14

$\mathrm{kDa}, 19 \mathrm{kDa}, 38 \mathrm{kDa}, 65 \mathrm{kDa}$ that influence the occurrence ofvariationsinsensitivity and specificityindiagnosing TB. The presence of MTB antigen characteristics can be used to identify monoclonal antibodies. MTB protein-64 (MPT 64) as a specific antigen secreted by MTB complex (Mycobacterium tuberculosis, Mycobacterium africanum, and Mycobacterium bovis) during its MTB growth. The protein weight $24 \mathrm{kDa}$ and this protein are only found in MTB and can be used for identification MTB through antigen-antibody binding. MPT64 protein can be identified if the number of germs is at least $10^{-5} \mathrm{CFU} / \mathrm{ml}$ and can use isolate samples from both pulmonary and extrapulmonary that are cultured on liquid or solid media [12].

PNB test is a test used to distinguish Mycobacteria other than M. tuberculosis (MOTT) and MTb. The substance of PNB is an organic compound and a precursor of 4-aminobenzoic acid (PABA) which can produce folic acid. MOTT can metabolize PNB by reducing PABA as folic acid. While MTb is not able to reduce PNB to PABA, so it cannot grow in the PNB-LJ media, while MOTT can grow because it is able to metabolize PABA [13].

The use of solid media as a culture of MTB is recommended by the World Health Organization (WHO). Sputum as a specimen of MTB examination due to sputum as a result of activity in the lungs. The culture method is a bacteriological examination method that is more sensitive than the microscopic examination of TB. The sensitivity of culture results from $80 \%$ to $85 \%$ of sensitive seedlings compared with microscopic smear examination (30-60\%) because the culture can detect up to 50 colonies per $\mathrm{ml}$ of sputum and sensitivity is quite high $98 \%$ in $80 \%$ of cases suspect TB. The obstacle that occurs in culture is the relatively long reading time (4-8 weeks) due to the low metabolic activity of MTB due to generation time of about $20 \mathrm{~h}$ and to grow in culture media, it takes $100-1000$ cells $/ \mathrm{ml}$ of sputum [14].

Multidrug-resistant and extensively drug drug-resistant TB constitutes serious problems for the efficient control of the disease stressing the need to investigate resistance to first- and second-line drugs. Conventional methods for detecting drug resistance in MTB and the most commonly used proportion method on Löwenstein-Jensen medium or Middlebrook agar require a minimum of 3-4 weeks to produce results. The WHO has approved the GeneXpert MTB/RIF assay to detect RIF resistance directly from specimens, as well as line-probe assays such as GenoType MTBDR plus to improve MDR-TB detection. In addition, the GenoType MTBDR assay is available for the rapid detection of second-line TB drug resistance. Conventional MTB DST using solid media such as LJ medium is slow, whereas liquid medium based methods such as the Mycobacteria Growth Indicator Tube 960 system (MGIT) can provide first-and second-line DST results in approximately 10 days after MTB is isolated in sufficient concentrations for indirect DST; however, MGIT is prohibitively expensive in resource-constrained settings [15].

\section{The drug-resistance pattern of MTB Isolate against seromucous of the snail, chitosan, and SIRE}

The diagnosis of TB can be made based on clinical symptoms, chest X-ray, microscopic examination of smear sputum, and smear culture on culture media as well as the sensitivity test of MTB isolates to ATD. Drug sensitivity testing (DST) is a microbiological examination that needs to be done to support the treatment of TB infection. The benefit of the examination is that it can be used to identify MTB sensitivity to determine the therapeutic regimen and to obtain MTB sensitivity data in the context of MDR-TB surveys in an area. The sensitivity of MTB can be used as a therapy guide for patients; it can also support the MTB resistance survey in an area. The drug resistance pattern of MTB isolates against seromucous of snail, chitosan, and SIRE, as shown in Table 2.
Based on Table 2, it showed that all MTB isolates in patients suspect TB are resistant against seromucous of the snails and chitosan that it is compared with SIRE. The drug-resistance pattern of all MTB isolates that $100 \%$ were resistant against freeze-dried seromucous of the snail, chitosan, and varies with ATD as follows: SM $80 \%$, INH $0 \%$, RIF $0 \%$, and EB $80 \%$. This is thought to be related to the mechanism of action of snail seromucous and chitosan which has not been effective. The resistance level of each organism is influenced by internal factors and external factors of the cell. Internal factors include physiological factors, namely the structure and composition of cell walls, resistance factors associated with resistance coding genes. While external factors include environmental factors, namely chemical and biological-physical agents that can affect the physiology of microbial cells. In addition, the factor causing the ineffectiveness of the test preparation as an alternative to ATD is the quantitative factor of the test preparation which is not optimal dosage. The ineffectiveness as an alternative to ATD is due to the biochemical, physical properties of the preparations as the solubility and dispersion compound active of seromucous freeze-dried and chitosan which is unable to penetrate the permeability of MTB cells so that the dosage of the test preparation used is not optimal as bactericidal agents. Besides that, the factor of physiological characteristics of MTB cells as AFB cells that have specific characteristics compared to other physiological bacterial cells with the presence of mycolic acid in cell walls acts as a factor for the virulence of MTB bacterial cells. The sensitivity test results of MTB isolates against SIRE showed that RIF and INH were the most effective ATD because all MTB isolates were sensitive so that there was no growth in LJ medium with the drug.

Each type of ATD has a different mechanism of action so that it has an effect on the effectiveness of bactericide as ATD. RIF and SM are drugs as first-line ATD which are commonly used today. The mechanism of action of SM interferes with the translation process by binding to $16 \mathrm{~s}$ rRNA in protein synthesis. INH inhibits the synthesis of mycolic acid so that INH as the most effective ATD for the treatment and prevention of TB. INH resistant strains often appear with a frequency of around $90 \%$ and the resistance is caused by mutations in one of the katG, inhA, or ahpC genes. INH in cells will turn into active in an oxidized form due to activation of the enzyme catalase-peroxidase (KatG) which is encoded by the kat $\mathrm{G}$ gene. The katG gene encodes the enzyme catalase-peroxidase which activates INH as a prodrug so that mutations in the gene cause the enzyme to become inactive. Other mechanisms of resistance to INH and ethionamide (ETH) are changes in the expression of drug activators, redox changes, drug inactivation, and efflux pump activation [16]. RIF as bactericide by inhibiting nucleic acid synthesis by binding to the $\beta$ RNA polymerase subunit in the RNA transcription process. The resistance of MTB to RIF reaches $95 \%$ and occurs due to the mutation of the $r p o B$ gene that encodes the $\beta$ RNA polymerase subunit as an important component in the transcription process. The transcription process is inhibited because RIF is specifically bound to the $\beta$ RNA polymerase subunit. EB is a bactericide by interfering with carbohydrate metabolism and cell wall biosynthesis. While PZA as an analog of nicotinamide structure is bactericidal because pyrazinoic acid as a result of the activity of the pyrazinamidase enzyme formed under acidic conditions. PZA resistance occurs due to mutations in the pncA gene that causes loss of pyrazinamidase activity (PZAase) so that the mechanism of action of PZA becomes inactive when entering the cell MTB resistance to EB occurs due to mutations in the $e m b B$ gene that encodes arabinosiltransferase so that biosynthesis or wall polymerization is inhibited Arabinan cells as arabinogalactan components and the occurrence of the accumulation of decaprenyl-phospho-arabinose lipid carriers [17]. The potential of snail mucus in the wound healing process was due to its active substance content. Snail mucus contained chemicals such as Achasin isolates, heparan sulfate, and calcium. The Achasin isolates were beneficial as antibacterial and analgesic, while calcium played a role in hemostasis. The effects of snail mucus as antibacterial and anti-inflammatory accelerated the inflammatory phase, either 
Table 2: Resistance of Mycobacterium tuberculosis isolates against seromucous of snail, chitosan, and SIRE

\begin{tabular}{|c|c|c|c|c|c|c|c|c|c|}
\hline No. & Sample & Dilution & $\begin{array}{l}\text { Negative } \\
\text { control }\end{array}$ & Chitosan & $\begin{array}{l}\text { Seromucoid of } \\
\text { snail }\end{array}$ & Streptomycin (S) & Isoniazid (I) & Rifampicin (R) & Ethambutol (E) \\
\hline \multirow[t]{2}{*}{1} & 122 & $10^{-3}$ & $2+$ & $2+$ & $2+$ & $2+$ & Negative & Negative & $2+$ \\
\hline & & $10^{-5}$ & $1+$ & $1+$ & $1+$ & $1+$ & Negative & Negative & $1+$ \\
\hline \multirow[t]{2}{*}{2} & 172 & $10^{-3}$ & $1+$ & $4+$ & $4+$ & $1+$ & Negative & Negative & Negative \\
\hline & & $10^{-5}$ & 15 colonies & $3+$ & $3+$ & 5 colonies & Negative & Negative & Negative \\
\hline \multirow[t]{2}{*}{3} & 197 & $10^{-3}$ & $2+$ & $3+$ & $2+$ & Negatif & Negative & Negative & $2+$ \\
\hline & & $10^{-5}$ & $1+$ & $2+$ & $1+$ & Negatif & Negative & Negative & $1+$ \\
\hline 4 & & $10^{-5}$ & $3+$ & $3+$ & $3+$ & $3+$ & Negative & Negative & $3+$ \\
\hline \multirow[t]{2}{*}{5} & 218 & $10^{-3}$ & $2+$ & $3+$ & $3+$ & $2+$ & Negative & Negative & $2+$ \\
\hline & & $10^{-5}$ & $1+$ & $2+$ & $2+$ & $1+$ & Negative & Negative & $1+$ \\
\hline \multicolumn{2}{|c|}{$\%$ Resistance } & & 100 & 100 & 100 & 80 & 0 & 0 & 80 \\
\hline
\end{tabular}

the proliferation phase of wound healing. The seromucous of snail preparations that have been used in this study as freeze-dried preparation because based on the results of research that is being done shows that snail seromucous freeze-dried has been significant activity on lymphocyte proliferation in vitro compared to snail seromucous without freeze-dried. The results of previous studies showed that snail seromucous concentration of $100 \%$ is antibacterial against S. aureus, Candida albicans, and Pseudomonas aeruginosa [18]. The difference in the variation of antibacterial agents because it is influenced by inoculum strains related to the level of resistance of microorganisms as well as the type of antibacterial Achasin protein of genetic expression each snail strain varies. Antibacterial and antifungal test results of meat protein extract from seven different types of snail with diffusion and dilution methods showed that varied minimal inhibition concentration and influenced by snail's ecological conditions [19]. Various types of proteins or known as Achasin proteins in snails have important biological functions, including as a protein-binding receptor (enzyme) for bacteria. Snail mucous is able to be as antibacterial against Streptococcus mutans and E. coli and inhibits the growth of methicillin-resistant $S$. aureus [20]. The concentration of $100 \%$ snail mucus is bacteriostatic against the growth of $S$. aureus and Salmonella typhosa [21]. The effectiveness of bactericidal and bacteriostatic snail mucus varies with isolates Staphylococcus Sp., Streptococcus Sp., and Pseudomonas Sp. [22]. A number of protein lectins are known to be contained in snails, namely selectin, galectin, C-type lectins, and fibrinogen-related proteins secreted by snails after an infection which has a role in the process of pathogen agglutination [23]. The results of the characterization of snail protein seromucous profile SDS-PAGE method showed that there were three subunits of protein, namely the range of 55-72 $\mathrm{kDa}$ as the Achasin sulfate group that played an antimicrobial role and 1 specific protein subunit $43 \mathrm{kDa}$ as an adhesive protein which was still further investigated [24].

Chitosan synthesis uses samples of shrimp shell or crab shells through the process of deacetylation with $60 \% \mathrm{NaOH}$ at $60-100^{\circ} \mathrm{C}$; deproteinization with $3.5 \% \mathrm{NaOH}$, decalcification with $\mathrm{HCl} 2 \mathrm{~N}$, and color removal with acetone and $2 \% \mathrm{NaOCl}[25]$. Chitosan has biocompatible, biodegradable, non-toxic, antimicrobial, and hydrating agent properties. Chitosan also influences the process of blood clotting so that it can be used as a hemostatic and positive effect on wound healing.

The content of bioactive compounds in snail seromucous and chitosan can stimulate the function of cellular immunity, namely lymphocyte proliferation and the production of reactive oxygen intermediated macrophages. Seromucoid freeze-drying and chitosan preparations showed significant activity on lymphocyte proliferation in vitro compared to snail slime without freeze-drying. Chitosan 5\% gave the most effective result toward lymphocyte proliferation activity compared to $100 \%$ snail slime and $5 \%$ snail slime cream. The snail mucus cream $5 \%$ provides a higher proliferative activity than the $100 \%$ snail mucus. The mixture of chitosan $5 \%$ and snail slime $100 \%$; snail slime $5 \%$ cream showed optimum effectiveness against lymphocyte proliferation in vitro [26].
The effectiveness of a bactericidal or bacteriostatic drug against MTB isolates can be influenced by the physiological bacterial cells as genetic factors related to the level of resistance or cell virulence and mutation process caused by mutagenic agents in physical chemistry from environmental factors. MTB cells have mycolic acid (trehalose dimycolate) which plays an important role in the interaction of pathogens with the host. Mycolic acid functions were equivalent to lipopolysaccharides in Gram-negative bacterial cells. Mycolic acid influences the function of macrophages which inhibits the fusion of macrophages in host cells against pathogens. The presence of mycolic acid content in MTB plays an important role in the level of resistance of germs to host immune cells and drugs.

The immune response also plays an important role in MTB infection. The immune system plays an effective role in most infections. The risk of developing TB increases if there are conditions that interfere with the immune system such as coinfection with HIV. Macrophages cells play an important role in the immune system host by phagocytosis of cellular antigens. Bacteria in the lungs will be phagocytosed by alveolar macrophages, but MTB found in macrophages can change the acidity of the environment so that the phagosome maturation process stops. This results in a phagosome not being able to fuse with lysosomes and MTB cannot be destroyed and subsequently replicates in macrophages. MTB cells secrete virulence factors such as ESAT-6, CFP-10, and MPT-64. MTB cells have many protein antigens, some of which are in the cytoplasm, cell walls, and others are secreted. Proteins secreted into the extracellular environment by MTB, namely ESAT-6, CFP-10, MPB-70, MPT-64, MPT-63, and MPT-80 can cause an immune response and have diagnostic values [27].

Treatment of TB with ATD so far has been given the right ATD; however, lately, there are many strains of MTB resistant to two or more ATD known as MDR-MTB strains. The prevalence of MDR-TB and extensively drug-resistant TB is higher in the case of recurrent TB treatment compared to the initial TB case and the variation in the level of TB germ resistance to ATD is influenced by age, sex, and region [28]. There are side effects in MDR-TB therapy and the correlation between cure rates and resistance to ATD so that a psychological, social management approach is needed in MDR-TB patients and the presence of a bacterial profile related to resistance against antibiotics against TB treatment. This is due to the patient's ignorance of the disease, poor patient compliance, administration of monotherapy or ineffective drug regimens, inadequate doses, poor instructions, low medication regularity, poor patient motivation, irregular drug supply, poor bioavailability, and poor quality the drug contributes to the occurrence of secondary drug resistance.

The characteristics of respondents by sex and age are the majority of male respondents and productive adult age that is 26 years -52 years. Respondents generally suspect TB is more common in men because the occurrence of cases of TB infection is closely related to the respondent's internal factors or physiological factors, namely genetic, nutritional, stressor, respondent behavior, and external factors, namely 
cultural, social, economic, and the environment includes relationships, education level, employment, welfare, and living conditions. In general, the percentage of smokers' respondents is bigger the male than female. While the productive age to adulthood is the age of optimum activity undertaken by respondents related to socioeconomic conditions. It was also following the medical record data at Surakarta City Central General Hospital in 2016 to 2019 that showed the characteristics of respondents according to the sex and age of the respondent suspect TB was male and occurs relatively in productive age to adulthood, which was 26-55 years [29].

The number of TB cases in Indonesia in 2017 was 420,994 cases and occurred in male smokers $68.5 \%$ while in women $3.7 \%$. The incidence rate of TB in men is 1.4 times greater than in women due to male smokers being more susceptible to TB risk factors and non-compliance factors to take drugs [30]. TB cases in women are generally found to be a late diagnosis, whereas men are more likely to come to health services when TB treatment is free [31]. Age is significantly related to the MDR$\mathrm{Tb}$ incidence rate. Ages 45-64 years have a risk level of TB is 2.4 times compared to the age group of 15-24 years. MDR-Tb is common in people over 41 years and $<65$ years but has a weaker and more heterogeneous relationship in patients under 45 years [32].

Pulmonary tuberculosis (PTB) continues to be a public health problem, especially in developing countries, including Indonesia. The necessity use of multidrug regimens of ATD in PTB treatment has been associated with increased risk of drug hypersensitivity reactions (DHRs). The necessity utilization of multidrug regimens for TB treatment has been associated with increased risk of DHR. DHR has various clinical manifestations and it is unpredictable. It should avoid unnecessary drug interruption or suboptimal treatment in order not to lead a treatment failure or resistance [33]

The effect of the use of ATD that is not effective because of the noncompliance of patients in taking medication, the use of an effective ATD regimen, can have an impact on the emergence of MTB strain resistance, so it is known as MDR-Tb. There are side effects in MDR-Tb therapy and the correlation between cure rates and resistance to ATD, so there is a need for a social psychological management approach in MDR-Tb patients and bacterial profiles associated with antibiotic resistance to TB treatment. The use of other ATD alternative drugs with higher toxicity, namely ETH, aminosalicylic acid, cycloserine, capreomycin, ciprofloxacin, or ofloxacin can cause the emergence of MTB strains that are more resistant to ATD so that the failure of TB therapy becomes high and the difference in the effectiveness of ATD types to strain variations MTB.

Limitations of the study are the relatively small number of samples used and the specificity and sensitivity of the examination method. Therefore, it is necessary to conduct further research related to the greater number of samples and the formulation of test preparations in combination with ATD.

\section{CONCLUSION}

The snail seromucous (8000 mg/l) and chitosan $(800 \mathrm{mg} / \mathrm{l})$ are not as effective as alternative ATD against MTB isolates.

\section{ACKNOWLEDGMENT}

The author appreciates all the participants, who gave the willingness to participate and all support to this study.

\section{AUTHORS' CONTRIBUTIONS}

Yusup Subagio Sutanto designed the study, making of protocol, and managed the work done. Magdalena Sutanto performed the study and data analysis. Agnes Sri Harti prepared the formulation and completed the manuscript writing. Nony Puspawati prepared a management sample and laboratory test.

\section{CONFLICTS OF INTEREST}

The author declared that there are no conflicts of interest related to this study.

\section{AUTHORS' FUNDING}

The authors declare that there is no source of funding

\section{REFERENCES}

1. Zhuang J, Coates CJ, Zhu H, Zhu P, Wu Z, Xie L. Identification of candidate antimicrobial peptides derived from abalone hemocyanin. Dev Comp Immunol 2015;49:96-102.

2. Dang VT, Benkendorff K, Green T, Speck P. Marine snails and slugs: A great place to look for antiviral drugs. J Virol 2015;89:8114-8.

3. Dolashka P, Dolasshki A, Velkova L, Stevanovic S, Molin L, Traldi P, et al. Bioactive compounds isolated from garden snails. J BioSci Biotechnol 2015;:147-55.

4. Mandala AP, Harti AS. Effectiveness of $100 \%$ Snail Mucus (Achantina fulica) and 5\% Cream Preparation for Long-term Healing Wound Healing (Grade A) in vivo. Surakarta: Final Report, Departement of Nursing, Kusuma Husada Surakarta School of Health Science; 2014.

5. Harti AS, Nurhidayati A, Handayani D. The potential of rice bran and chito-oligosaccharide as natural prebiotic on traditional tempeh in Indonesia. Int J Biosci Biochem Bioinform 2013;3:654-6.

6. Harti AS, Nurhidayati A, Handayani D, Estuningsih, Kusumawati HN, Haryati DS. The fortification tempeh of rice bran chitosan as functional food antihy-percholesterolemia in Indonesia. Int $\mathrm{J}$ Biosci Biochem Bioinform 2014;4:423-7.

7. Harti AS, Haryati DS, Sunarto, Setyaningsih W, Yatmihatun S The potential chito-oligo-saccharide (COS) as natural prebiotic and preservatives on synbiotic tofu in Indonesia. Int J Pharm Med Biol Sci 2015;4:204-8.

8. Octaviana U, Maryati A, Fatimah S, Harti AS. Chitosan Biomembrane as Sanitary Pads. Jakarta: Final Report of Creativity Students Program, Department High Education Indonesia; 2015.

9. Harti AS, Sulisetyawati SD, Murharyati A, Oktariani M, Wijayanti IB. The effectiveness of snail slime and chitosan in wound healing. Int $J$ Pharm Med Biol Sci 2016;5:76-80.

10. Indonesian Pulmonary Doctors Association. Guidelines for Tuberculosis Diagnosis and Management in Indonesia. Jakarta: Indonesian Pulmonary Doctors Association; 2006.

11. Akhavan R, Meshkat Z, Jamehdar S. Comparing the frequency of Mycobacterium tuberculosis with direct microscopy and culture methods. Jundishapur J Microbiol 2012;6:95-6.

12. Kanade S, Nataraj G, Suryawanshi R, Mehta P. Utility of MPT 64 antigen detection assay for rapid characterization of mycobacteria in a resource constrained setting. Indian J Tuberc 2012;59:92-6.

13. Haryanto B. Benefits of TB Ag MPT 64 Immunochromatography test for the Differentiation of Mycobacterium tuberculosis Complex and Mycobacterium non Tuberculosis Complex. Jakarta: Thesis, Educational Program of Clinical Microbiology Specialist in the Faculty of Medicine. University of Indonesia; 2015.

14. Retnoningrum DS, Roga FK. Mechanisms of molecular level of resistance to several drugs in Mycobacterium tuberculosis. Acta Pharm Indones 2004;29:92-5.

15. Martin A, Paasch F, Von Groll A, Fissete K, Almeida P, Varaine F, et al. Thin-layer agar for detection of resistance to rifampicin, ofloxacin and kanamycin in Mycobacterium tuberculosis isolates. Int J Tuberc Lung Dis 2009; $13: 1301-4$

16. Vilchèze $\mathrm{C}$, Jacobs WR Jr. Resistance to isoniazid and ethionamide in Mycobacterium tuberculosis: Genes, mutations, and causalities. Microbiol Spectr 2014;2:MGM2.

17. Kiepiela P, Bishop KS, Smith AN, Roux L, York DF. Genomic mutations in the katG, inhA and aphC genes are useful for the prediction of isoniazid resistance in Mycobacterium tuberculosis isolates from Kwazulu Natal, South Africa. Tuber Lung Dis 2000;80:47-56.

18. Harti AS, Puspawati N, Putriningrum R. Antimicrobial bioactive compounds of snail seromucous as biological response modifier immunostimulator. Microbiol Indones 2019;13:56-63.

19. Harti AS, Puspawati N, Putriningrum R. Characterization of Physicochemistry, Microbiological and Profile of Seromucous Protein Snails (Achatina fullica Ferussac) as in vitro Biological Response Modifiers. Surakarta: Proceeding the $10^{\text {th }}$ International Seminar of Indonesian Society for Microbiology $\left(10^{\text {th }}\right.$ ISISM $)$ and $12^{\text {th }}$ Congress of the Indonesian Society for Microbiology (12 ${ }^{\text {th }}$ CISM). PERMI; 2019. 
20. Ulagesan S, Kim HJ. Antibacterial and antifungal activities of proteins extracted from seven different snails. Appl Sci 2018;8:1362.

21. Anggraeni Y. Preparation and Carcarization of Chitosantripolyphosphate Cross-connecting Film that Contains Aystosides as Bioactive Bandages for Wounds. Jakarta: Thesis, Masters Program in Pharmaceutical Sciences, FMIPA University of Indonesia; 2012.

22. Huda M, Marhamah. Effect of snail mucus (Achantina fulica) on the growth of gram-positive and gram-negative Bacteria. Dep Health Anal Tanjungkarang Health Polyt J Health Anal 2016;5:.

23. Etim LB, Chuku A, Godwin AO. Antibacterial properties of snail mucus on Bacteria isolated from patients with wound infection. Br Microbiol Res J 2015;11:1-9.

24. Perez WP, Dina F, Iwang Y. Effect of snail mucus (Achatina fulica) on the number of fibroblast cells in the healing of vegetable wounds. Experimental study on the skin of mice (Mus musculus). J Vet Med 2007;23:139-44.

25. Ibrahim KA, El-Eswed BI, Abu-Sbeih KA, Arafat TA, Al Omari MM, Darras FH, et al. Preparation of chito-oligomers by hydrolysis of chitosan in the presence of zeolite as adsorbent. Mar Drugs 2016;14:43.

26. Harti AS, Murharyati A, Sulisetyawati DS, Oktariani M. The effectiveness of snail mucus (Achatina fulica) and chitosan toward limfosit proliferation in vitro. Asian J Pharm Clin Res 2018;11:85-8.
27. Burkovski A. Cell envelope of corynebacteria: Structure and influence on pathogenicity. ISRN Microbiol 2013;2013:935736.

28. Wu X, Yang J, Tan G, Liu H, Liu Y, Guo Y, et al. Drug resistance characteristics of Mycobacterium tuberculosis isolates from patients with tuberculosis to 12 antituberculous drugs in China. Front Cell Infect Microbiol 2019;9:1-11.

29. Sutanto YS, Sutanto M, Harti AS. Prediction of Determinants of the Occurrence of Mycobacterium tuberculosis Isolate Resistance in Tuberculosis Patients. Surakarta: Research Report, Department of Pulmonology and Respiratory Medicine, Faculty of Medicine, Sebelas Maret University of Surakarta; 2020.

30. Health Ministry Republic of Indonesia. Tuberculosis. Jakarta: Health Ministry Republic of Indonesia; 2018.

31. Nakagawa, Ozasa K, Yamada N, Shimouchi A, Ishikawa, Bam DS. Gender difference in delays to diagnosis and health care seeking behavior in a rural area of Nepal. Int $J$ Tuberc Lung Dis 2001;5:24-31

32. Farihatun S, Machmud PB. Determinant factors of drop out among multi drugs resting Tuberculosis patients at Jakarta Province. Int J Trop Dis 2018;7:87-92.

33. Suryana K. Drug provocation test as a diagnostic approach for hypersensitivity reaction to antituberculosis drugs: A report of two cases. Asian J Pharm Clin Res 2020;13:1-4 